\title{
AMBULASI DINI DENGAN PENYEMBUHAN LUKA SECTIO CAESAREA DI RSUD dr. SOEKARDJO KOTA TASIKMALAYA
}

\author{
${ }^{1}$ Wiwi Puspitasari, ${ }^{2}$ Wiwin Mintarsih P., \& ${ }^{3}$ Sinar Pertiwi \\ 1,2,3 Jurusan Kebidanan Poltekkes Kemenkes Tasikmalaya \\ wiwipuspitasari31@yahoo.com
}

\begin{abstract}
Abstrak
Tujuan penelitian adalah mengetahui hubungan ambulasi dini dengan penyembuhan luka post sectio caesarea. Metode penelitian yang digunakan adalah analitik korelasional dengan pendekatan crossectional. Populasi penelitian ini ibu bersalin dengan kasus Sectio Caesarea di RSUD dr.Soekardjo pada bulan Desember - Februari tahun 2017, teknik Purposive Sampling yaitu sebanyak 84 orang. Hasil penelitian menunjukkan bahwa 77 orang $(91,7 \%)$ melaksanakan ambulasi dini, sedangkan 7 orang $(8,3 \%)$ tidak melaksanakan ambulasi dini, keadaan luka operasi Sectio Caesarea pada kategori sembuh yaitu 73 orang $(86,9 \%)$. Hasil pengujian statistik menggunakan uji Chi Square dengan $\alpha=0,000(\alpha<0,05)$, maka Ho ditolak yang berarti ada hubungan ambulasi dini dengan penyembuhan luka Sectio Caesarea di RSUD dr. Soekardjo Tasikmalaya. Ambulasi dini dapat mempercepat luka operasi section caesarea.
\end{abstract}

Kata Kunci : Ambulasi dini, penyembuhan luka

\section{Abstract}

The purpose of research is to know the relationship of early ambulation with wound healing post sectio caesarea. The research method used is correlational analytics with crossectional approach. The population of this research is mother with case of Sectio Caesarea in RSUD dr.Soekardjo in December-February 2017, Purposive Sampling technique is 84 people. The results showed that 77 people $(91.7 \%)$ had early ambulation,while 7 people $(8.3 \%)$ did not carry out early ambulation, the condition of the wound of Sectio Caesarea surgery in the cured category was 73 people (86.9\%). The results of statistical tests using Chi Square test with $\mathrm{a}=0.000(\mathrm{a}<0.05)$,then $\mathrm{Ho}$ is rejected which means there is an association of early ambulation with wound healing Sectio Caesarea in RSUD dr. Soekardjo Tasikmalaya. Early ambulance can accelerate the surgery of the caesarea section.

Keywords: Early ambulance, wound healing.

\section{PENDAHULUAN}

Persalinan dengan Sectio Caesarea dapat menjadi salah satu penyebab terjadinya infeksi apabila perawatan yang dilakukan tidak benar. Komplikasi yang dapat terjadi pada ibu dengan persalinan Sectio Caesarea adalah infeksi puerperal seperti kenaikan suhu pada masa nifas, peritonitis, sepsis, dan sebagainya. Komplikasi yang lain adalah perdarahan, luka kandung kencing, embolisme paruparu (Wiknjosastro, 2007). Komplikasi pembedahan selama sectio caesarea
$>11 \%$ (kira-kira $80 \%$ minor dan 20\% mayor (Benson, 2009).

Jahitan operasi caesar memiliki resiko untuk terjadinya infeksi yang bisa saja muncul selama berada dalam masa penyembuhan dari operasi caesar yang telah lakukan (Hardianti, 2014).

Ambulasi dini pada ibu post partum pelaksanaannya tergantung pada kondisi pasien, apabila pasien melakukan persalinan dengan normal, bisa dilakukan setelah 2-4 jam setelah persalinan dan ibu yang menjalani Caesar bisa melakukan 
Ambulasi 8 jam sesudah bersalin (Manuaba, 2009). Asuhan Kebidanan dan Standar Prosedur Operasional (SPO) Rumah Sakit dr.Soekardjo Tasikmalaya tentang mobilisasi dini bagi pasien Post Sectio Caesarea menyebutkan bahwa pelaksanaan mobilisasi dini dilakukan mulai 6 jam post operasi.

Rumah Sakit Umum Daerah (RSUD) Kota Tasikmalaya merupakan rumah sakit rujukan yang ada di Kota Tasikmalaya. Berdasarkan hasil studi pendahuluan yang dilakukan penulis di Ruang Pengelola data dan Pelaporan (PPL) Rumah Sakit Umum (RSUD) Kota Tasikmalaya penulis menemukan bahwa dari 574 persalinan dengan Sectio Caesarea selama tahun 2015 dan pada periode Januari-Juli 2016 angka persalinan dengan Sectio Caesarea meningkat hingga 716 kasus.

Berdasarkan hasil studi pendahuluan yang dilakukan pada tanggal 7 dan 21 September 2016 di Rumah Sakit Umum Daerah (RSUD) Kota Tasikmalaya di peroleh hasil bahwa tiga dari lima ibu post Sectio Caesarea sudah mengetahui tentang ambulasi dini. Namun mereka belum melaksanakan ambulasi dini sesuai dengan SPO penatalaksanaannya dinilai masih belum sesuai dengan SPO. Sehingga berdampak pada proses pemulihan kondisi badan dan penyembuhan luka setelah terjadinya proses melahirkan.

Data yang telah diperoleh dari hasil studi pendahuluan mengenai infeksi yang terjadi pada ibu nifas post Sectio Caesarea pada tahun 2015 terdapat 7 kasus infeksi yang terdiri dari 2 kasus Operasi bersih, 4 kasus Operasi kotor, 1 Operasi bersih terinfeksi. Pada tahun 2016 terdapat 4 kasus yang terdiri dari 2 Operasi Bersih, 2 Operasi kotor. Mekipun dalam junlah tidak terlalu banyak apabila tidak ditangani secara benar bisa berakibat fatal dengan kesehatan ibu. (RSUD dr.Soekardjo 20152016)

Oleh karena itu peneliti merasa tertarik untuk melakukan penelitian tentang hubungan pentalaksanaan ambulasi dini dengan penyembuhan luka ibu post partum Sectio Caesarea.

\section{METODOLOGI PENELITIAN}

Penelitian ini adalah penelitian korelasi dengan pendekatan cross sectional. penelitian ini bertujuan untuk mengukur antara variabel bebas dan terikat pada waktu yang bersamaan. Penelitian dilaksanakan di Rumah Sakit Umum dr. Soekardjo Kota Tasikmalaya pada bulan Maret sampai April tahun 2017.

Populasi penelitian adalah semua ibu bersalin dengan kelompok kasus Sectio Caesarea di RSUD dr.Soekardjo pada bulan Maret sampai April tahun 2017. Pengambilan sampel dalam penelitian ini menggunakan Purposive Sampling yang berjumlah 84 orang.

Variabel penelitian adalah variabel bebas (independen) yaitu mobilisasi dini dan variabel terikat (dependen) yaitu penyembuhan luka Post Sectio Caesarea. Instrumen yang digunakan berupa lembar observasi, yang dibuat oleh peneliti yang terdiri dari nomor rekam medik, diagnosa post sectio caesarea pada ibu nifas yang persalinannya melalui Sectio Caesarea

Analisis univariat yang digunakan untuk memberikan gambaran distribusi frekuensi dari variabel. Untuk mengetahui adanya hubungan antara variabel yang diteliti maka menggunakan analisa data dengan rumus chi kuadrat.

\section{HASIL PENELITIAN}

Tabel 1. Distribusi Frekuensi Umur Ibu yang Mengalami Sectio Cesarea

\begin{tabular}{ccc}
\hline Umur & F & $\begin{array}{c}\text { Persentasi } \\
\%\end{array}$ \\
\hline$<20$ Tahun & 5 & 6,0 \\
\hline 20-35 Tahun & 66 & 78,6 \\
\hline$>$ 35 Tahun & 13 & 15,5 \\
\hline Jumlah & 84 & 100 \\
\hline
\end{tabular}

Berdasarkan Tabel 1. menunjukkan bahwa umur ibu yang mengalami Sectio 
Caesarea ada pada kategori umur 20-35 tahun yaitu sebanyak 66 orang $(78,6 \%)$.

Tabel 2. Distribusi Frekuensi Pelaksanaan Ambulasi Dini pada Ibu yang Mengalami Sectio Caesarea

\begin{tabular}{lcc}
\hline Ambulasi Dini & F & $\begin{array}{c}\text { Persentasi } \\
\%\end{array}$ \\
\hline Tidak & 7 & 8,3 \\
\hline Ya & 77 & 91,7 \\
\hline Jumlah & 84 & 100 \\
\hline
\end{tabular}

Berdasarkan Tabel 2. menunjukkan bahwa pelaksanaan ambulasi dini pada ibu yang mengalami Sectio Caesarea sebanyak 77 orang $(91,7 \%)$ melaksanakan ambulasi dini, sedangkan 7 orang $(8,3 \%)$ tidak melaksanakan ambulasi dini

Tabel 3. Distribusi Frekuensi Keadaan Luka pada Ibu yang Mengalami Sectio Caesarea

\begin{tabular}{lcc}
\hline Keadaan Luka & F & $\begin{array}{c}\text { Persentasi } \\
\%\end{array}$ \\
\hline Tidak Sembuh & 11 & 13,1 \\
\hline Sembuh & 73 & 86,9 \\
\hline Jumlah & 84 & 100 \\
\hline
\end{tabular}

Berdasarkan Tabel 3. menunjukkan bahwa keadaan luka operasi Sectio Caesarea ada pada kategori sembuh yaitu sebanyak 73 orang $(86,9 \%)$, sedangkan 11 orang $(13,1 \%)$ tidak sembuh.

Tabel 4. Hubungan Pelaksanaan Ambulasi Dini dengan Penyembuhan Luka

\begin{tabular}{lccc}
\multicolumn{4}{c}{ Sectio Caesarea } \\
\hline \multirow{2}{*}{ Ambulasi } & \multicolumn{2}{c}{ Penyembuhan } & \multirow{2}{*}{ Jumlah } \\
\cline { 2 - 3 } & Tidak & Sembuh & \\
\hline Tidak & 7 & 0 & 7 \\
\hline Ya & 4 & 73 & 77 \\
\hline Jumlah & 11 & 73 & 84 \\
\hline
\end{tabular}

Hasil pengujian statistik dengan menggunakan uji Chi Square diperoleh nilai hitung sebesar 0,000 , jika dibandingkan dengan nilai $\alpha(0,05)$ maka nilai hitung lebih kecil daripada nilai $\alpha$ $(0,000<0,05)$, maka Ho ditolak yang berarti ada hubungan antara pelaksanaan ambulasi dini dengan penyembuhan luka post Sectio Caesarea di RSUD dr. Soekardjo Kota Tasikmalaya.

\section{PEMBAHASAN}

Ambulasi dini merupakan suatu upaya mempertahankan kemandirian sedini mungkin dengan cara membimbing penderita untuk menggerakkan badan atau melatih kembali otot-otot dan sendi pasca operasi, memperbugar pikiran dan mengurangi dampak negatif dari beban psikologis yang tentu saja berpengaruh terhadap pemulihan fisik dalam mempertahankan fungsi fisiologis.

Hal ini sejalan dengan pendapat Smeltzer, Suzanne C (2008) mengungkapkan bahwa ambulasi adalah kemampuan seseorang untuk bergerak secara bebas, mudah, teratur dan mempunyai tujuan dalam rangka pemenuhan kebutuhan hidup sehat. Ambulasi adalah mengacu pada kemampuan seseorang untuk bergerak dengan bebas, dan iambulasi mengacu pada ketidakmampuan seseorang untuk bergerak dengan bebas (Potter \& Perry, 2005).

lbu yang luka sembuhnya lama disebabkan karena beberapa faktor diantaranya adalah : asupan nutrisi yang kurang, umur, kurangnya mobilisasi, sedangkan ibu yang cepat luka sembuhnya disebabkan karena aanya tindakan lanjutan yang dilakukan oleh perawat dalam merawat penyembuhan luka operasi Sectio Caesarea. Tindakan ini berupa perawatan yang intensif kepada klien.

Ada beberapa hal yang berhubungan dengan penyembuhan luka operasi Sectio Caesarea diantaranya adalah: 1) Pemberian sitostatika, obat penekan reaksi imun, kortikosteroid dan sitotoksik mempengaruhi penyembuhan luka dengan menekan pembelahan fibroblast dan sintesis kolagen, 2) Tehnik penjahitan luka 
yang tidak dilakukan lapisan demi lapisan akan mengganggu penyembuhan luka, 3) Kebersihan diri seseorang akan mempengaruhi proses penyembuhan luka, karena kuman setiap saat dapat masuk melalui luka bila kebersihan diri kurang, 4) Gangguan konsep diri : Body image bisa terjadi pada pasien post laparatomy karena adanya perubahan sehubungan dengan pembedahan. Intervensi perawatan terutama ditujukan pada pemberian support psikologis, ajak klien dan kerabat dekatnya berdiskusi tentang perubahanperubahan yang terjadi dan bagaimana perasaan pasien setelah operasi.

Hasil pengujian statistik dengan menggunakan uji Chi Square diperoleh nilai hitung sebesar 0,000, jika dibandingkan dengan nilai $\alpha(0,05)$ maka nilai hitung lebih kecil daripada nilai $\alpha$ $(0,000<0,05)$, maka Ho ditolak yang berarti ada hubungan antara pelaksanaan ambulasi dini dengan penyembuhan luka post Sectio Caesarea di RSUD dr. Soekardjo Kota Tasikmalaya.

Adanya hubungan ini disebabkan karena ambulasi dini merupakan suatu tindakan aktifitas yang dapat mengantisipasi terjadinya kekakuan otot yang menyebabkan kekakuan dalam pergerakan, membantu melancarkan peredaran darah kedaerah yang luka sehingga membantu proses penyembuhan luka atau jaringan baru dan mengurangi rasa nyeri, mencegah terjadinya trombosis dan tromboemboli karena dengan ambulasi sirkulasi darah normal / lancar resiko terjadinya trombosis dan tromboemboli dapat dihindari, menghindari resiko komplikasi hospitalisasi seperti dekubitus. Dengan melakukan ambulasi dini jumlah skor dari skala penyembuhan luka semakin sedikit, ini menandakan bahwa luka tekan telah membaik atau menyembuh dengan cepat.

Ambulasi merupakan faktor yang utama dalam mempercepat pemulihan dan dapat mencegah komplikasi pasca bedah. Banyak keuntungan yang bisa diraih dari latihan di tempat tidur dan berjalan pada periode dini pasca bedah. Ambulasi dini sangat penting dalam percepatan hari rawat dan mengurangi resiko karena tirah baring lama seperti terjadinya dekubitus, kekakuan atau penegangan otot-otot di seluruh tubuh dan sirkulasi darah dan pernafasan terganggu, juga adanya gangguan peristaltik maupun berkemih. (Carpenito, 2000).

Ambulasi segera secara bertahap sangat berguna untuk proses penyembuhan luka dan mencegah terjadinya infeksi serta trombosis vena. Bila terlalu dini melakukan ambulasi dapat mempengaruhi penyembuhan luka operasi. Jadi ambulasi secara teratur dan bertahap yang didikuti dengan latihan adalah hal yang paling dianjurkan.

Tanggung jawab atas kesehatan diri sendiri, termasuk juga harus dapat mencapai tingkat kemandirian maksimal, dalam hal ini adalah melakukan ambulasi yang sesuai dengan kondisi pasien. Ambulasi dini bermanfaat untuk mempertahankan ambulasi fisik secara optimal, maka system saraf, otot dan skeletal harus tetap utuh dan berfungsi dengan baik (Potter., Perry, 2006).

$\mathrm{Hal}$ ini sejalan dengan yang dilakukan oleh Kamid (2010) yang menyebutkan bahwa Adanya hubungan antara intensitas nyeri dengan kemampuan ambulasi dini ini disebabkan karena intensitas nyeri yang dirasakan oleh pasien dapat mempengaruhi terhadap kemampuan ambulasi pasien. Ambulasi dini pada pasien post operasi sangat diperlukan untuk mencegah kekakuan otot, membantu melancarkan peredaran darah sehingga dapat mempercepat proses penyembuhan luka, mencegah terjadinya tromboemboli serta menghindari resiko komplikasi dekubitus.

\section{KESIMPULAN}

Karakteristik pasien post sectio cesarea di RSUD dr.Soekardjo Kota Tasikmalaya apabila dilihat dari aspek 
umur didominasi oleh umur 20-35 tahun sebanyak $78,6 \%$ dari total keseluruhan.

Pelaksanaan ambulasi pada ibu Sectio Caesarea di RSUD dr. Soekardjo Kota Tasikmalaya ada pada kategori dilaksanakan, dan sesuai dengan SOP yang ada di RSUD dr.Soekardo Tasikmlaya.

Penyembuhan luka Sectio Caesarea di RSUD dr. Soekardjo Kota Tasikmalaya ada pada kategori sembuh.

Ada hubungan pelaksanaan ambulasi dini dengan penyembuhan luka Sectio Caesarea di RSUD dr. Soekardjo Kota Tasikmalaya

\section{SARAN}

Disarankan bagi tenaga kesehatan agar dapat memonitoring secara penuh pelaksanaan ambulasi dini agar bisa dilaksanaakan sesuai dengan SPO yang berlaku.

\section{DAFTAR PUSTAKA}

Agustina, H. R., (2009). Perawatan Luka Modern.

Anggriani, Sri. dkk., (2014). Jurnal

Kesehatan Diagnosisi Hubungan

Mobilisasi Dini Terhadap

Penyembuhan Luka Post Op Sectio

Caesarea di RSUD Salewangan

Maros. http://library.stikesnh.ac.id diakses pada tanggal 2 juni 2017 jam 20.00 WIB.

Angraini, (2010). Asuhan Kebidanan Masa Nifas. Yogyakarta : Pustaka Rihama.

Bahiyatun, (2009). Buku Ajar Asuhan Kebidanan Nifas Normal . Jakarta : EGC.

Benson, R.C., (2009). Buku Saku Obstetri dan Ginekologi. Jakarta: EGC.

Boyle, M., (2009). Seri Praktik Kebidanan Pemulihan Luka. Jakarta: EGC.

Carpenito, L.J., (2009) Buku saku asuhan keperawatan. Jakarta :EGC

Dube, J., (2014). Effect of planned early recommended ambulation technique on selected post caesarean biophysiological health parameters.
Original Article. Department of Obstetrics and Gynecology, Krishna Institue of Medical Sciences.

Ghayut, Y., (2014) Ambulasi dini pada pasien dengan anestesi spinal dan anestesi umum. Diakses di https://www.scribd.com pada tanggal 8 Juni 2017.

Hidayat, S., (2006). Buku ajar ilmu bedah Edisi 3.EGC Jakarta

http://dspace.library.uph.edu:8080/bitstrea m/123456789/1727/4/Chapter\%201.p $\mathrm{df} /$ penyembuhan/luka di akses pada tanggal 15 september 2016.

http://repository.usu.ac.id/bitstream/123456 789/40151/4/Chapter\%20II.pdf /masa/nifas diakses pada tanggal 10 September 2016 .

http://www.fkep.unpad.ac.id/2009/01/peraw atan-luka-modern/universitas Padjadjaran.

Manuaba, I., (2009). Ilmu Kebidanan, Penyakit Kandungan dan Keluarga Berencana Untuk Pendidika Bidan. Jakarta: EGC. 